\title{
THREE CASES OF DUODENAL OBSTRUCTION IN THE NEW-BORN
}

\author{
BY \\ C. P. LAPAGE, M.D., F.R.C.P., ANNIE E. SOMERFORD, M.D., Ch.B., and \\ FANNY HOWE, M.B., Ch.B. \\ (From the Department of Diseases of Children, Manchester University.)
}

Congenital obstruction of the upper part of the alimentary tract is a rare condition. Its frequency has been given by Davis and Poynter ${ }^{1}$ as 1 in 20,000 subjects, but Sheldon ${ }^{2}$ states that in 6,000 autopsies in children it was found in 28 instances. The recognition of such obstruction during life is of importance as successful operations for its relief have been recorded. In the absence of operative interference the average duration of life is six days, although some cases may live considerably longer than this.

Symptomatology.-Congenital duodenal obstruction gives rise to various signs and symptoms, the chief of which are vomiting, visible gastric peristalsis, constipation and jaundice.

Vomiting usually begins in the first few hours of life and persists : it is forcible or projectile in character. Bile is usually found in the vomit ${ }^{3,4}$, and sometimes blood is also present ${ }^{1}$. Even when the obstruction is above the level of the bile papilla, the vomit may be bile-stained owing to the presence of an accessory bile-duct. Vomiting is very persistent : occasionally a fced may be retained, but if so a larger vomit than usual follows the next feed. Gastric peristalsis is usually to be observed. Constipation is commonly present. Its severity depends upon the site of the obstruction. If below the bile papilla, constipation will be absolute except for the passage of some débris from the intestinal wall. If above the papilla, there may be small stools, brownish in colour. Smellie ${ }^{3}$, however, reports a case of stenosis at the duodeno-jejunal flexure in which normal coloured, though constipated, stools were passed. Jaundice is not uncommon in cases of congenital duodenal obstruction.

Diagnosis. - Cases of congenital duodenal obstruction have to be differentiated from those of congenital pyloric stenosis and congenitel obliteration of bile-ducts. In the former there are forcible vomiting and visible gastric peristalsis, but the vomit does not contain obvious bile, and jaundice is absent. 
Also the onset of the vomiting tends to be considerably later than in congenital duodenal obstruction. In cases of congenital obliteration of the bile-ducts, jaundice is the predominating symptom and vomiting is of secondary importance.

Type of duodenal obstruction.-Congenital duodenal obstruction may be intrinsic or extrinsic in origin. In the intrinsic cases the obstruction may occur at various levels, and may even be multiple, in which case there is little hope of successful relief by operation. MacClennan ${ }^{5}$ recognizes three types: (a) a gap in the continuity of the gut wall ; (b) a partition in the bowel ; (c) a partial obstruction from narrowing of the lumen of the duodenum.

Extrinsic obstruction may be due to adhesions ${ }^{6}$, bands 7 , or to torsion and volvulus ${ }^{8}$.

Treatment.-Operation holds out a distinct possibility of success. Successful results have been recorded by Smellie $^{3}$, Jewesbury and Page ${ }^{6}$, Sweet and Robertson ${ }^{4}$, Fockens $^{9}$, Ernst $^{10}$, and Richter ${ }^{11}$. The case reported by Sweet and Robertson is of particular interest in that the infant, a very frail and emaciated baby, survived two operations, anterior gastro-jejunostomy followed by duodeno-jejunostomy, and ultimately made a complete recovery.

\section{Authors' cases.}

We here record three cases of duodenal obstruction in none of which was operation considered feasible. The full pathological and anatomical reports on the third case show it to be one of particular interest owing to its unusual origin.

Case 1.-G.M., male. The child was a Mongol but appeared physically healthy at birth. Though breast-fed he began vomiting on the fifth day. Vomiting occurred after every feed, it was coffee-ground in colour and was projectile in character coming down the nose. The mother stated that she had observed peristalsis. The stools were sometimes greenish in colour and sometimes constipated.

On examination the child was seen to be a typical Mongol. The abdomen was protuberant but peristalsis was not observed. There was a noticeable swelling stretching across the abdomen from the left hypochondrium, passing below the umbilicus and ending on the right side. It was not very resonant, fairly superficial, comparatively soft and did not seem to pit. During the examination the baby vomited through its nose; the vomit smelt of sour milk.

The question of operation was considered but rejected as the infant was very frail. Death took place six days later.

AUTOPSY.-The œesophagus was apparently normal. The stomach was :slightly dilated but the pylorus was normal. To the naked eye the gastric mucosa and the wall generally was normal. The duodenum measured $7 \cdot 5 \mathrm{~cm}$. in length and $5.25 \mathrm{~cm}$. at the greatest breadth. It was somewhat boat shaped and was much dilated. The mucosa did not show any abnormality but there was slight thickening of the muscular coat. The peritoneal coat was apparently normal. Owing to the fact that the specimen had been excised from the 
rest of the gut at the stenosed point it was impossible to give any idea of the size of the opening in the constricted portion.

Case 2.-(Case notes by Dr. E. Holmes, Kendal.) Baby P., male. The baby appeared well on the first day of life and was fed on breast milk. Urine and meconium were passed. On the second day vomiting of green watery fluid commenced and sterile water with glucose was substituted. A glucose saline was also given and was repeated at 6 -hourly intervals. On the third day the baby still vomited bile-stained fluid and the stools were green. The temperature rose to $102 \cdot 2^{\circ}$. On the fourth day gastric lavage was instituted and it was noticed that the capacity of the stomach was much increased and that it was impossible to wash the returning fluid free from bile. Death took place on the fifth day.

Autopsy.-Only the thorax and abdomen were explored, and apart from the lesion in the alimentary tract the organs were normal. The stomach and pyloric orifice were apparently normal, the latter not being dilated. The duodenum was somewhat boat-shaped and was much dilated especially at its distal end. The measurements were $7.5 \mathrm{~cm}$. in length, $1.3 \mathrm{~cm}$. in width. On opening up the duodenum it was found to contain a little undigested material and a considerable quantity of thin mucus; its mucous membrane and wall were apparently normal. At the duodeno-jejunal flexure the lumen of the gut was occluded, the occlusion being complete although there was no interruption in the continuity of the wall of the bowel. The rest of the small intestine, cæcum and ascending colon were all collapsed.

Case 3. - Baby B., (from Dr. Lawrie). The baby was big at birth and there was a history of bilious vomiting. When the child was admitted to hospital on the tifth day of life, operation was not considered advisable owing to its general condition. With lavage the stools became more normal and the stomach contents became cleared. The child, however, was in a very weak condition and died without there being any opportunity for operative measures.

The interest of this case lies in the autopsy record which showed that the condition was due to a band connected with blood vessels. The post mortem report, and the anatomical description for which we are indebted to Professor Stopford and Miss F. Howe, are appended.

Autopsy.- The stomach was greatly distended and on gentle manipulation ruptured immediately, discharging bile-stained contents. The pylorus was patent and showed no hypertrophy. The small intestine apart from the duodenum was collapsed and the large intestine appeared to be rather atrophic. The first and second parts of the duodenum were considerably dilated. There was a band in the mesentery passing across the distal end of the duodenum, anchoring it firmly to the posterior abdominal wall. On section and microscopical examination this band was shown to consist of connective tissue carrying minute branches of the superior mesenteric vessels and also containing lymphoid tissue. The band was continued downwards in the mesentery apparently as a vessel to supply the lower part of the ileum about $2 \frac{1}{2}$ inches from the ileo-cæcal junction. The duodenum beyond the band was collapsed and its diameter measured about one quarter that of the duodenum above the band, thus demonstrating that the stenosis was due to the presence of the band.

Dissection. (Fig. 1 and 2.)-The superior mesenteric vessels (D) and accompanying nerves emerge from the lower border of the pancreas and cross 
the distal part of the duodenum as it passes behind the root of the mesentery at $(\mathbf{M})$. There is no pressure on the duodenum at this point.

The duodenum in the region of the junction of its first, second and third parts is crossed by a firm rounded band (x) of about $3 \mathrm{~mm}$. in diameter which arises from the superior mesenteric vessels. The band crosses the gut anteriorly and winds round its right border to its posterior surface. Here a portion of the band widens out into a rounded mass of lymphoid tissue (A) about $5 \mathrm{~mm}$. in diameter, through which it obtains attachment to the posterior abdominal wall, thus anchoring down and constricting the duodenum. The

Fig. 1.

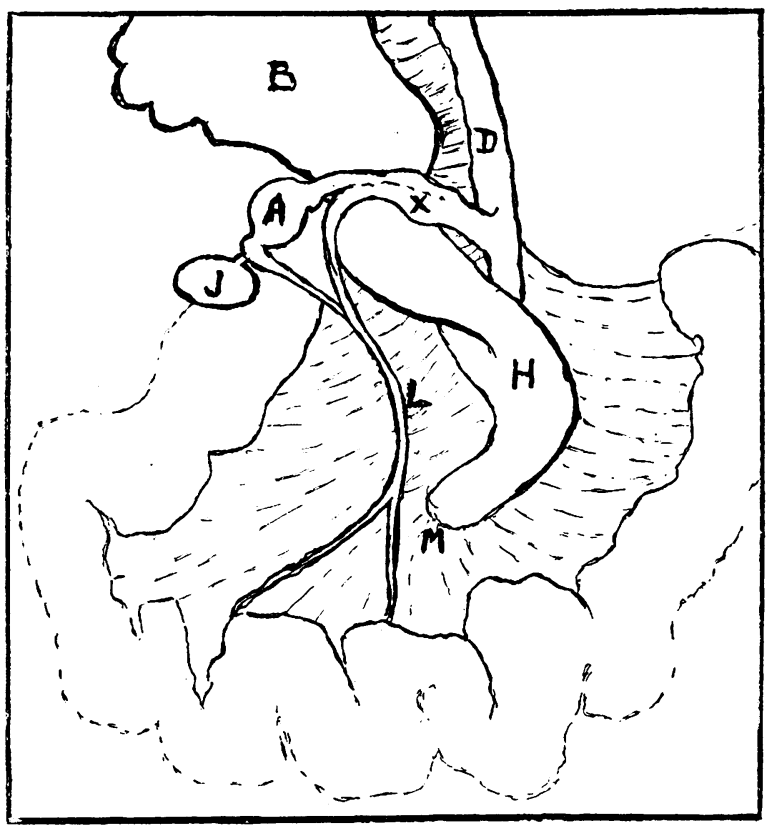

Case 3 : Diagram Representing dissection of band.

$\mathrm{X}=$ Constricting band.

$\mathrm{D}=$ Superior mesenteric vessels.

$\mathrm{B}=$ Duodenum dilated above strict

$\mathbf{H}=$ Projecting loop of duodenum.
$\mathrm{L}=$ Vessels, continuous with band, running to supply terminal part of ileum.

$\mathrm{M}=$ Root of mesentery.

A, $J=$ Lymphoid tissue.

portion of the band not blending with the lymphoid mass continues $(\mathrm{L})$ down in the mesentery where it bifurcates and runs towards the terminal part of the ileum.

In the region of the constricting band the duodenum has acquired a definite mesentery and becomes freely movable forming a short projecting $\operatorname{loop}(\mathrm{H})$.

Histologically the band $(\mathrm{X})$ is composed of connective tissue transmitting small bloodvessels and running alongside these a mass of lymphoid tissue. 
'The two elements, viz., lymphoid tissue and blood vessels, become continuous respectively with the lymphoid mass (A) and the vessels (L) rumning to supply the ileum. The mass $(\mathrm{J})$ also consists of lymphoid tissue.

Cause of Obstruction.-Two factors seem to be concerned, the presence of a constricting band and the abnormal mobility of the duodenum.

A band consisting of connective tissue carrying minute branches of the superior mesenteric vessels has arisen before the latter have crossed the third

\section{Fig. 2.}

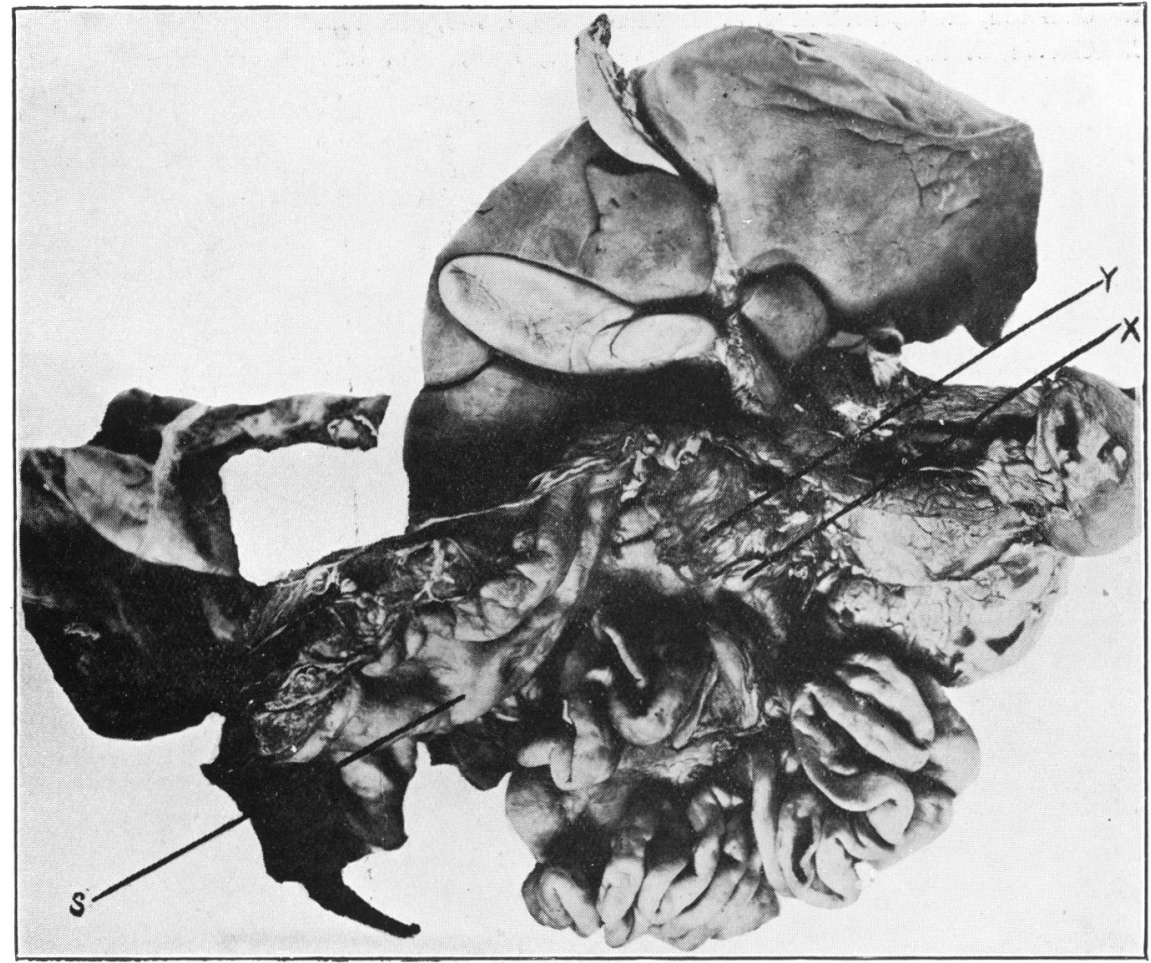

Photograph illustrating Case 3.

$\mathrm{S}=$ Stomach. $\quad \mathrm{Y}=$ Dilated duodenum. $\quad \mathrm{X}=$ Band.

part of the duodenum. The band has developed additional thickness due to the presence of lymphoid tissue.

Such a band would be likely to produce stenosis but a second factor, namely, the mobility of the duodenum renders this more probable. The presence of lymphoid tissue which is usually found developmentally fixed to the posterior abdominal wall, together with the mobility of the duodenum: produces a balance in favour of pressure stenosis of the duodenum by the band 


\section{REFERENCES.}

1. Davis, D. L., \& Poynter, C. W. M., Surg. Gynec. Obst., Chic., 1922, XXXIV,

2. Sheldon, W. P. H., Arch. Dis. Childh., London, 1926, I, 279.

3. Smellie, J. M., Brit. J. Dis. Child., London, 1924, XXI, 192.

4. Sweet, G. B., \& Robertson, C., Arch. Dis. Childh., Lond., 1927, II, 186.

5. MacClennan, A., Brit. Med. J., London, 1927, ii, 818.

6. Jewesbury, R. C., \& Page, C. M., Proc. R. Soc. Med., Lond., 1923, XV1, (Sect. Dis. Child.), 50.

7. Higgins, T. T., \& Paterson, D., Arch. Dis. Childh., Lond., 1926, I, 285.

8. Baker, A. H., \& Mizen, V., Brit. Med. J., London, 1926, i, 1031.

9. Fockens, P., Zentralbl. f. Chir., Leipsic, 1911, XXXVIII, 532.

10. Ernst, N. P., Brit.Med. J., London, 1916, i, 644.

11. Richter, H. M., Surg. Gynec. Obst., Chic., 1913, XVII, 397.

12. Cameron, H. C., Brit. Med. J., London, 1925, i, 765, 815, 872.

13. Garvin, J. A., Am. J. Dis. Child., Chicago, 1928, , 109. 